\title{
OTEL ÇALIŞANLARININ PSİKOLOJİK GÜÇLENDİRME İLE ÖRGÜTSEL BAĞLILIKLARI ARASINDAKİ İLIŞKİ ${ }^{*}$
}

\author{
Ufuk ISSIK \\ Yavuz Kağan YASIM²
}

\begin{abstract}
Atıf/O: Işıłk, Ufuk ve Yasım, Yavuz Kağan (2017). Otel Çalışanlarının Psikolojik Güçlendirme ile Örgütsel Bağllıkları Arasındaki İlişki. Hitit Üniversitesi Sosyal Bilimler Enstitüsü Dergisi, Yıl 10, Sayı 2, Aralık 2017, ss.1581-1594

Özet: Amaç: Bu çalıșmanın amacı otel çalıșanlarının psikolojik güçlendirme ile örgütsel bağlılıkları arasındaki ilişkinin belirlenmesidir. Araştırma Yöntemi: Veriler Ordu İli Ünye bölgesinde otellerde çalsşan 216 çalışandan anket yoluyla toplanmiş ve SPSS programiyla analiz edilmiştir. Bulgular: Yapılan korelasyon analizi sonucunda iki değişken arasında orta düzeyde pozitif yönlü anlamlı bir iliş̧ki tespit edilmiştir. Sonuç ve Öneri: Bu çalışma ile turizm sektöründe çalışanlara yönelik örgütsel politikaların, sektörün başarısında önemli bir kriter olduğu görülmektedir.
\end{abstract}

Anahtar Kelimeler: Psikolojik Güçlendirme, Örgütsel Bağllık, Turizm Sektörü

\section{The Relation Between Psychological Reinforcement and Organizational Engagement Of Hotel Employees}

Citation/O: Işık, Ufuk ve Yasım, Yavuz Kağan (2017). The Relation Between Psychological Reinforcement and Organizational Engagement Of Hotel Employees, Hitit University Journal of Social Sciences Institute, Year 10, Issue 2, December 2017, pp.1581-1594

Abstract: Aim: The aim of the study is to determine the relation between psychological reinforcement and organizational engagement of the hotel employees. The methodology of the research : The data has been collected through a survey conducted by 216 employees being employed in the hotels around Unye town of Ordu province and analyzed with SPSS The findings : In the end of correlation analysis conducted, a mid-level, positive-directed meaningful relation has been established. The result and suggestion: It is observed that the organizational policies applied to the employees working in tourism sector are a significant criteria in sector success.

Keywords: Psychological reinforcement, Organizational engagement, Tourism sector

Makale Gelis Tarihi: 22.06.2017/ Makale Kabul Tarihi: 30.10.2017

1 Ögrr. Gör., Ordu Üniversitesi, Ünye Meslek Yüksekokulu, e-posta: ufuk5852@hotmail.com

2 Yrd. Doç. Dr., Hitit Üniversitesi, İ.I.B.F., Çalışma Ekonomisi, e-posta: ykyasim@gmail.com

"Bu makale 14-15 Nisan 2017 tarihlerinde Gaziantep'te yapılan VI. Ulusal II. Uluslararası Doğu Akdeniz Turizm Sempozyumunda sunulan bildirinin genişletilmiş halidir. 


\section{GİRIŞ}

1970'lerin ikinci yarısından sonra kendisini göstermeye başlayan küreselleşme süreci, iktisadi işletmelerin teknolojik yapılarının yanısıra organizasyonel yapılarında da önemli değişiklere yol açmıştır. Personel yönetimi yerini insan kaynaklarına birakmıştır. Yoğun rekabette başarılı olabilmek için işletmeler, çalışanların kendilerini öğrenmeye ve geliştirmeye adadıkları, karar sürecine azami katılımın sağlandığı, güven ikliminin ve açık iletişimin hâkim olduğu bir ortamı esas alan organizasyon yapisı oluşturmak için gayret sarf etmektedirler (Çekmecioğlu ve Eren, 2007). Bu gayretlerden bir kısmı kendisini psikolojik güçlendirme olarak göstermektedir. Çalışanlara yönelik yürütülen bir takım faaliyetler ve alınan kararların sonucunda, çalışanlarının kendilerini örgüt içinde daha güvenli, mutlu ve huzurlu hissetmeleri, onların örgütün hedeflerine motivasyonlarını artıracaktır. Psikolojik olarak güçlenmiş çalışanların örgüte bağlllıkları da artacaktır. Bu yüzden emek yoğun bir sektör olan turizm sektöründe çalışanlara yönelik örgütsel politikalar büyük önem taşımaktadır.

\section{A. Kuramsal Çerçeve:}

\section{1.Örgütsel Bağlılık:}

Bağl1lık kelime anlamı itibariyle belirli bir varlığa karşı geliştirilen duygusal bir yönelme ya da sosyal bir birime karşı beslenen ait olma duygusu olarak tanımlanmaktadır (Naktiyok ve Polat, 2016; 4). Tarihsel olarak bakıldığında, örgütsel bağll1ık ilk kez Whyte tarafından 1956 yılında "The Organization Man" başlıklı eserinde kullanılmıştır. Whyte, örgüte bağlı işgöreni tanımlayarak, örgütte çalışan kişiyi sadece çalışan değil ayrıca örgüte ait olan kişi olarak tanımlamıştır (Whyte, 1956;11-12). Kavram daha sonra başta Porter olmak üzere Mowday, Steers, Allen, Meyer, Becker gibi pek çok araştırmacı tarafından geliştirilmiştir. 1956 yılından beri süre gelen araştırmalar, bağlılık konusunda çok sayıda ve birbirinden farklı kavramın bulunduğunu ortaya koymaktadır. Örgütsel bağlılık, çalışanın kabulü ve onun psikolojik bir sözleşmeyle işe girmesiyle başlar. Örgütün bir üyesi olarak hedefler, amaçlar ve işin gerektirdikleri konusunda bilgi ve deneyim edinmesiyle gelişir. Bu açıdan bakıldığında örgütsel bağl1lık, bir kişinin belirli bir örgüt ile kimlik birliğine girerek oluşturduğu güç birliğidir (Gül, 2002; 37-38).

Örgütsel bağl11ı̆̆1 Mowday vd. (1979;225-226), bireyin organizasyon içindeki kimlik gücü, mevcut örgütsel üyeliği korumak için gösterdiği güçlü istek 
olarak tanımlarken, Morrow $(1983 ; 491)$ ise örgütün hedeflerini benimseme ve örgütte kalma isteği olarak tanımlamıştır. Morrow, örgütsel bağımlılığın Protestan iş ahlaklıyla olan ilişkisine dikkat çekmiş, bu doğrultuda mesleğine önem verme ve işe bağl11ı̆ın önemini ifade etmiştir. Ayrıca örgütsel bağl1lığın demografik özellikler, cinsiyet, işe katılım, deneyim gibi faktörlerden etkilendiğini vurgulamıştır.

Allen ve Meyer (1984) Örgütsel bağl1lı̆̆1; duygusal bağlılık ve devam bağl11ığ1 olmak üzere iki faktöre bağlı olarak sınıflandırmıştır, bu sınıflandırmaya daha sonra 3. bir alt boyut olarak "normatif bağlllık" eklenmiştir (Allen ve Meyer, 1990;2-3).

Duygusal Bağlılık: Çalışanın örgüte olan duygusal bağını ifade etmektedir. Çalışan kişinin yazılı sözleşmeden çok psikolojik sözleşmeyle çalışmasıdır. Çalışanın örgütün hedeflerini benimsemesi ve arada oluşan aidiyet duygusudur (Allen,Meyer, 1990;2-3).

Devam Bağlılığı: Bireyin örgüt içindeki kazanımları (statü, maaş) ve örgütten ayrılması durumda karşılaşacağı maliyetleri (emek, zaman) göz önünde bulundurarak örgüt üyeliğinin sürdürülmesi isteğidir (Allen, Meyer, 1991; 64).

Normatif Bağl1lık: Çalışanlarda oluşan ahlaki bir görevi yerine getirdiği duygusu ve örgütsel bağl1lı̆̆ın doğru bir davranış olduğuna gösterilen inançtır (Allen, Meyer, 1991; 67).

\section{Psikolojik Güçlendirme:}

Personel güçlendirme kavramı ilk kez Kanter (1977) tarafından yönetim literatürüne kazandırılmıştır (Demirel, Yücel: 2012: 21). Rosabeth Kanter (1977) "Men and Women of the Corporation" adlı kitabında güçlendirmeyi, "bir bireyin amaçlara ulaşmak için mevcut kaynaklardan yararlanma ve bağımsız şekilde kararlar alma yeteneği” olarak tanımlamıştır (Tolay, Sürgevil, Topoyan: 2012: 451). Bawen ve Lawyer ise psikolojik güçlendirme kavramını "çalışanların, organizasyonun dört girdisini paylaşmaları" olarak tanımlar (Yüksel, Erkutlu: 2003: 131-132). Bunlar:

- Organizasyonun performansına ilişkin bilginin paylaşımı,

- Çalışanların organizasyonun performansını anlamalarını ve katkıda bulunmalarını sağlayacak olan bilginin paylaşımı, 
- Organizasyonun performansı ile ilgili ödüllerin paylaşımı,

- Organizasyonun yön ve performansını etkileyecek karar alma yetkisinin paylaşımıdır.

Literatürde güçlendirme davranışının Thomas ve Velthouse göre anlam, etki, yeterlilik ve seçim olmak üzere dört boyutu bulunmaktadır.

Anlam: Bir görevin yapılış amacının işgören için taşıdığı değerdir. Bu değer tamamen işgörenin sahip olduğu idealler ve standartlara bağlı olarak işgören tarafından belirlenmektedir. Bu durumda anlam, üstlenilen iş rolünün gerekleri ile işgörenin değerleri, inançları ver davranışları arasındaki uyumu ifade etmektedir (Karahan, Y1lmaz: 2010: 159).

Etki: Çalışanın işin yöntem veya sonuçları üzerindeki etkiye sahip olma derecesidir (Ceylan, Çelik, Emhan: 2015: 172). Kişinin işinde stratejik, yönetimsel ve operasyonel çıktıları etkileyebilme düzeyidir (Gümüştekin, Emet: 2007: 97-98).

Yeterlilik: Çalışanların işlerini iyi yapabilmeleri konusunda kendilerine ve yeteneklerine duydukları güven düzeyiyle ilgilidir (Tolay, Sürgevil, Topoyan: 2013: 5374). Bireyler yapabileceğine inandığı faaliyetlerde bulunup, inanmadığı faaliyetlerden kaçınmaktadır.

Seçim: İnsiyatif alma veya birisinin faaliyetlerin düzenlenmesi ile ilgili tercih duygusunu yansitır yani çalışanın görevdeki davranışlarında ve yeni girişimlerinde özerk olmasını (Yücel, Demirel: 2012: 22), diğer bir ifadeyle çalışanların işlerini nasıl yapacakları konusunda karar verme özgürlüklerini ve işleri üzerinde kontrol sahibi olmalarını ifade eder (Tolay, Sürgevil, Topoyan: 2013: 5374).

Güçlendirmenin doğasını, çalışanların kendilerini güçlenmiş hissetmelerine yol açacak faktörleri ve güçlendirilmiş bir işgücünün ortaya koyduğu sonuçları anlamak önemlidir (Yücel ve Demirel, 2012: 21). Psikolojik güçlendirme, yazında yeni araştırılan konulardan birisi olmasına rağmen birçok olumlu örgütsel davranışın öncülü olduğu ortaya konmuştur. Yapılan araştırmalarda psikolojik güçlendirmenin; iş tatmini, örgütsel bağl1lık, iş performans1, örgütsel vatandaşlık davranışları ve yenilikçi davranışlarla pozitif yönlü; işten ayrılma niyeti ve iş stresi ile negatif yönlü ilişkileri olduğu belirlenmiştir (Erdem vd.,2016: 163). 
Örgütsel bağl1lığ1 oluşturan öncüllerin belirlenmesine yönelik yapılan çalışmalarda; kişisel faktörler, iş ve rol ile ilgili beklentiler, örgütsel ve çevresel faktörlerin önemli olduğu vurgulanmış ve örgütsel faktörlerden birisi olarak da güçlendirme ifade edilmiştir (Kaplan, 2010). Ambad ve Bahron'un (2012), inşaat sektöründe çalışanlar üzerinde yaptığı çalışmada, Psikolojik güçlendirmenin alt boyutlarından etki ve özerkliğin örgütsel bağlılık üzerinde etkili olduğunu, anlam ve yetki alt boyutlarıyla örgütsel bağlılık arasında ise anlamlı bir ilişki olmadığını tespit etmiştir. Bogler ve Someck’in (2004) İsrail'de öğretmenler üzerinde; Çekmecioğlu ve Eren'in (2007) öğretim üyeleri üzerinde; Gohar, Bashir, Abrar ve Asghar'ın (2015) Pakistan'daki akademisyenler üzerinde yaptıkları araştırmalarda psikolojik güçlendirmenin örgütsel bağlılığ pozitif yönlü ve anlamlı olarak etkilediği görülmüştür (Erdem vd.; 2016:165). Erdem vd.(2016)' nin eğitim sektöründe öğretmen olarak görev yapan kamu çalışanlarına yönelik araştırmasında, P.G. 'nin yetkinlik boyutu hariç diğer üç alt boyutunun Ö.B.'1 pozitif yönlü ve anlamlı olarak etkilediği belirlenmiştir.

\section{B. Araştırma}

\section{Araştırmanın Amacı}

Bu çalışmanın amacı turizm sektöründe çalışanların psikolojik güçlendirme ile örgütsel bağl1lıkları arasındaki ilişkiyi tespit etmektir. TÜİK istatistiklerine göre Türkiye'de 2015 y1lı itibariyle hizmet sektöründe 13.891 .000 kişi istihdam edilirken tarım, sanayi ve inşaat sektörlerinde istihdam edilenlerin toplamı 12.729.000 olmaktadır. Hizmetler sektörünün en önemli unsurunun insan olduğu bilinen bir gerçektir. AKTOB (Akdeniz Turistik Otelciler ve İşletmeciler Birliği) 'un yayınladığı istatistiklere göre Türkiye'de 2013 yılında 1.298.000 kişi turizm sektöründe çalışmaktadır (AKTOB, 2014: 13). Gelişme potansiyeli yüksek olan bu sektörün istihdama büyük katkı sağladığ1 görülmektedir. Aynı şekilde çalışanların sektörün gelişmesine önemli katkılar sağladığı da yadsınamaz. Bu nedenle sektörde çalışanların örgütsel davranışları araştırılması gereken bir konu olmaktadır.

\section{2.Örneklem}

Bu araştırmanın evrenini Ordu İli Ünye İlçesindeki 3, 4 ve 5 yıldızlı otellerde çalışan personel oluşturmaktadır. Evrende toplam 280 personel bulunmaktadır. Tam sayım yönteminin uygulandığı bu araştırmada dağıtılan ve dönem anketlerin 216' sı değerlendirmeye alınmıştır. 


\section{Hipotezler}

Araştırmanın amacına uygun olarak;

H1: Psikolojik güçlendirme ile örgütsel bağlılık arasında pozitif yönlü anlamlı bir ilişki vardır.

H2: Psikolojik güçlendirmenin alt boyutları ile örgütsel bağlılığın alt boyutları arasında pozitif yönlü anlamlı bir ilişki vardır.

\section{4.Ölçekler}

\section{1.Örgütsel Bağlılık Ölçeği:}

$\mathrm{Bu}$ araştırmada Meyer ve Ailen tarafından geliştirilen üç boyutlu bağlllık ölçeği kullanılmıştır. Türkiye' de bir çok araştırmada Meyer ve Allen (1990) 'in geliştirdiği ölçeğin kullanıldığı görülmektedir. Tak ve diğ. (2011) nin 20022010 yıllarını kapsayan araştırmalarına göre Türkiye yapılan örgütsel bağlılık araştırmalarının \%64' ünde bu ölçeğin kullanıldığı görülmektedir. Aynı şekilde yabancı literatürde de aynı ölçek sıklıkla kullanılmaktadır. Ölçekte 7 soruyla duygusal bağlılık, 6 soruyla devam bağl1lığ1, 7 soruyla ise normatif bağl11ık alt boyutları ölçülmüştür.

\subsection{Psikolojik Güçlendirme Ölçeği:}

Psikolojik güçlendirmeyi ölçmek için Spreitzer (1995) tarafından hazırlanmış ölçek kullanılmıştır. Ölçekte 3' er soruyla anlamlılık, yeterlik, seçim (özerklik) ve etki alt boyutları olmak üzere toplam 12 soru yer almaktadır.

\section{Bulgular}

\subsection{Güvenilirlik Bulguları ve Tanımlayıcı İstatistikler}

Araştırmada kullanılan ölçeklerin Cronbach"s Alpha değerleri aşağıdaki gibidir. 
Tablo 1: Ölçeklerin Güvenilirlik Değerleri

\begin{tabular}{|c|c|}
\hline Ölçek & C. Alpha \\
\hline Psikolojik Güçlendirme & 0,829 \\
\hline Anlam & 0,952 \\
\hline Yeterlik & 0,843 \\
\hline Özerklik & 0,857 \\
\hline Etki & 0,783 \\
\hline Örgütsel Bağlllik & 0,885 \\
\hline Duygusal & 0,854 \\
\hline Devam & 0,701 \\
\hline Normatif & 0,844 \\
\hline
\end{tabular}

Cronbach's Alpha değerlerinin 0,80' in üzerinde çıkması halinde ölçek güvenilirliği yüksek seviyede olarak kabul edilmektedir (İslamoğlu ve Alnıçık, 2013: 278). Çalışmamızda ölçeklerin güvenilirliği yüksek seviyede ç1kmaktadır.

Tablo 2: Ölçeklerin Tanımlayıcı İstatistikleri

\begin{tabular}{|cc|c|c} 
& $\mathrm{N}$ & Ortalama & Std. Sapma \\
\hline Örgütsel Bağlılık & 216 & 3,4845 &, 44716 \\
\hline Duygusal Bağlılık & 216 & 3,0688 &, 40075 \\
\hline Devam Bağlılı̆ı & 216 & 3,6204 &, 57548 \\
\hline Normatif Bağlılık & 216 & 3,8526 &, 80069 \\
\hline Psikolojik Güçlendirme & 216 & 4,2774 &, 59334 \\
\hline Anlamlılık & 216 & 4,8673 &, 32925 \\
\hline Yetki & 216 & 4,8488 &, 33064 \\
\hline Özerklik & 216 & 3,7037 & 1,18023 \\
\hline Etki & 216 & 3,6898 & 1,18255 \\
\hline
\end{tabular}

Örgütsel bağlllık ölçeğine verilen cevapların ortalaması 3,48 ve psikolojik güçlendirme ölçeğine verilen cevapların ortalaması 4,28 puan çıkmıştır. Akgündüz vd. (2014) ' nin yine otel çalışanları üzerine yaptığı çalışmada 
psikolojik güçlendirme ölçeğinin ortalaması 4,43 puan çıkmıştır. Bu anlamda bulunan değer aynı sektördeki başka bir çalışma ile de uyum içerisindedir. Bu sonuçlar çalışanların yüksek bir psikolojik güçlendirilme ve örgütsel bağl1lık algısına sahip olduğunu göstermektedir.

Ölçeklere yönelik yapılan doğrulayıcı faktör analizinde, psikolojik güçlendirme ölçeğinin genel model uyumunu gösteren $x^{2} /$ SD oranı 3,245 (p<.05) bulunmuştur. Bu sonuç modelin genel uyumunun kabul edilebilir olduğunu göstermektedir. RMSEA =0,10, CFI=0,95 ise bulunmuştur. CFI' nin 0,95 ve üzerinde olması iyi uyumu gösterir (Meydan ve Şeşen, 2015: 34). Örgütsel bağll1ık ölçeğinin $\mathrm{x}^{2}$ / SD oranı 6,925 (p<.05), RMSEA değeri ise ,166 olarak tespit edilmiştir.

\subsection{Demografik Bulgular}

Örneklem grubuna ait demografik bulgular tablo 3 de görülmektedir.

Tablo 3: Örneklemin Demografik Bulguları

\begin{tabular}{llr|r|r} 
& & & & \\
\\
Cinsiyet & Kadin & 52 & \multicolumn{1}{c}{ Yüzde } & K. yüzde \\
\cline { 2 - 6 } & Erkek & 164 & 75,9 & 24,1 \\
\cline { 2 - 6 } & Total & 216 & 100,0 & 100,0 \\
\hline Yaş & $18-28$ & 106 & 49,1 & \\
\cline { 2 - 6 } & $29-39$ & 86 & 39,8 & 49,1 \\
\cline { 2 - 6 } & $40-50$ & 23 & 10,6 & 98,9 \\
\cline { 2 - 6 } & $51-60$ & 1 &, 5 & 100,0 \\
\cline { 2 - 6 } & Total & 216 & 100,0 & \\
\hline
\end{tabular}

Tablo 3' den görülmektedir ki, araştırmaya katılan personelin yaklaşı $\% 75$ ' i erkek ve \%49’u 18-28 yaş aralığındadır. 


\subsection{Korelasyon Analizi:}

Ölçeklerin Skewness- Kurtosis (Basıklık-Çarpıklık) değerleri -1/+1 aralığında çıkmaktadır. Bu yüzden ölçeklere parametrik analiz yöntemleri uygulanmıştır. (Tabachnick ve Fidel, 2013).

Yapılan Pearson Korelasyon analizinde Örgütsel bağlllık ile psikolojik güçlendirme arasında orta seviyede (r: 0,475, p < 0,05) anlamlı bir ilişki bulunmuştur. Böylece H1 hipotezi kabul edilmiştir. 'Psikolojik güçlendirmenin alt boyutları ile örgütsel bağlılığın alt boyutları arasında pozitif yönlü anlamlı bir ilişki vardır (H2)" hipotezinin doğrulanmasına yönelik yapılan analizde, psikolojik güçlendirmenin anlam alt boyutunun örgütsel bağl1lığın duygusal bağl1lı alt boyutu ile arasında anlamlı ilişki bulunmamıştır. Fakat diğer alt boyutlar arasında farklı seviyelerde pozitif yönlü anlamlı ilişki tespit edilmiştir.

Tablo 4: Korelasyon Analizi

\begin{tabular}{|c|c|c|c|c|c|c|c|c|c|}
\hline & & 1 & 2 & 3 & 4 & 5 & 6 & 7 & 8 \\
\hline \multirow{2}{*}{$\begin{array}{l}\text { Örgütsel } \\
\text { Bağlılık (1) }\end{array}$} & Pearson Corr. & 1 & & & & & & & \\
\hline & Sig. (2-tailed) & & & & & & & & \\
\hline \multirow{2}{*}{$\begin{array}{l}\text { Duygusal } \\
\text { (2) }\end{array}$} & Pearson Corr. &, $590^{* *}$ & 1 & & & & & & \\
\hline & Sig. (2-tailed) & ,000 & & & & & & & \\
\hline \multirow{2}{*}{ Devam (3) } & Pearson Corr. &, $751^{* *}$ &, $254^{\star *}$ & 1 & & & & & \\
\hline & Sig. (2-tailed) & ,000 & ,000 & & & & & & \\
\hline \multirow{2}{*}{ Normatif (4) } & Pearson Corr. &, $841^{* *}$ &, $267^{* *}$ & ,433** & 1 & & & & \\
\hline & Sig. (2-tailed) & ,000 & ,000 &, 000 & & & & & \\
\hline \multirow{2}{*}{$\begin{array}{l}\text { Psikolojik } \\
\text { Güç. (5) }\end{array}$} & Pearson Corr. &, $\mathbf{4 7 5} 5^{* *}$ &, $281^{\star *}$ &, $226^{\star *}$ &, $5_{04}^{* *}$ & 1 & & & \\
\hline & Sig. (2-tailed) & ,000 & ,000 & ,001 & ,000 & & & & \\
\hline \multirow{2}{*}{ Anlam (6) } & Pearson Corr. &, $321^{* *}$ & , 123 &, $150^{*}$ &, $368^{* *}$ &, $430^{* *}$ & 1 & & \\
\hline & Sig. (2-tailed) & ,000 & ,071 & ,027 & ,000 & ,000 & & & \\
\hline
\end{tabular}




\begin{tabular}{|c|c|c|c|c|c|c|c|c|c|}
\hline \multirow{2}{*}{ Yetki (7) } & Pearson Corr. &, $141^{*}$ &,$- 148^{*}$ & ,068 &, $281^{\star *}$ & ,408** &, $646^{\star k}$ & 1 & \\
\hline & Sig. (2-tailed) & ,038 & ,029 & ,323 & ,000 & ,000 & ,000 & & \\
\hline \multirow{2}{*}{ Özerklik (8) } & Pearson Corr. &, $383^{\star \star k}$ &, $306^{* *}$ &, $184^{\star *}$ &, $369^{* *}$ &, $889^{\star *}$ &, $212^{\star k}$ &, $184^{\star *}$ & 1 \\
\hline & Sig. (2-tailed) &, 000 & ,000 & ,007 &, 000 & ,000 & ,002 & ,007 & \\
\hline \multirow{2}{*}{ Etki (9) } & Pearson Corr. &, $441^{* *}$ & ,266 &, $208^{\star *}$ &, $462^{\star *}$ &, $886^{* *}$ &, $192^{\star k}$ &, $177^{\star \star k}$ &, $676^{* *}$ \\
\hline & Sig. (2-tailed) & ,000 & ,000 & ,002 & ,000 & ,000 & ,005 & ,009 & ,000 \\
\hline
\end{tabular}

** Korelasyon 0,01 seviyesinde anlaml *Korelasyon 0,05 seviyesinde anlaml1

\subsection{Regresyon Analizi}

Psikolojik güçlendirmenin örgütsel bağlllık üzerine etkisini görmek için regresyon analizi yapılmıştır. Regresyon modelinin anlamlı olup olmadığına ilişkin yapılan ANOVA analizinde sig. < ,01 bulunmuştur. Bu sonuç kurulan regresyon modellerinin anlamlı olduğunu göstermektedir (İslamoğlu ve Alnıaçık, 2013:363).

Tablo 5: Regresyon Analizi Model Özeti

\begin{tabular}{|c|c|c|c|c|}
\hline Model & $\mathrm{R}$ & $\mathrm{R}$ Kare & Uyarlanmiş $\mathrm{R}^{2}$ & $\begin{array}{c}\text { Tahmin edilen } \\
\text { Std. Hata }\end{array}$ \\
\hline DUYGUSAL &, $454^{a}$ & ,206 & , 191 &, 36048 \\
\hline DEVAM &, $247 \mathrm{a}$ & ,061 &, 043 & ,56296 \\
\hline NORMATİF &, $545^{\mathrm{a}}$ & ,297 & ,284 &, 67766 \\
\hline
\end{tabular}

a. Değişken: (Sabit), pg_etki, pg_yet, pg_anl, pg_özerk

Örgütsel bağl1lığın alt faktörleri olan duygusal, devam ve normatif bağlilığın bağımlı değişken olarak kabul edildiği analizlerde, personel güçlendirmenin alt boyutları bağımsız değişken olarak analize eklenmiştir. Regresyon analizi sonuçlarına göre personel güçlendirmenin duygusal bağl1lığın \%21' ini, devam bağl11ığının \%06' sını, normatif bağl11ı̆̆ı ise \%30' unu açıkladığı görülmektedir. Sonuçlar personel güçlendirmenin örgütsel bağll1ık üzerindeki açıklama gücünün zayıf olduğunu göstermektedir. Özellikle örgüt üyeliğini sürdürme arzusu üzerinde etkisinin nerdeyse bulunmadığı görülmektedir. 


\section{TARTIŞMA VE SONUÇ}

Psikolojik güçlendirme ve örgütsel bağlılık iki önemli örgütsel davranış şekli olarak karşımıza çıkmaktadır. Özellikle birebir müşteri ile etkileşim halinde olan Turizm sektöründe, çalışanların olumlu psikolojik alg1 ve davranışları, müşterilerin aldıkları hizmete bakış açılarını ve personel performansını doğrudan etkilemektedir. Bunun yanısıra konaklama sektöründeki örgütlerde, işgören devir hızının yüksek olması bu örgütlerde örgütsel bağl1lık kavramının önemini artırmaktadır (Çolakoğlu vd.,2009: 85).

$\mathrm{Bu}$ anlamda çalışan personele yönelik yürütülecek psikolojik güçlendirme faaliyetlerinin örgütsel bağl11ı̆̆1 $\operatorname{artıracağ}_{1}$, bu durumun ise yapılan araştırmalara göre iş tatminini ve motivasyon gibi olumlu çıktıları artırırken işten ayrılma niyeti, devamsızlık, yabancılaşma gibi olumsuz çıktıları da azaltacağı değerlendirilmektedir.

$\mathrm{Bu}$ çalışmada görülmektedir ki, iki kavram ve alt boyutları arasında pozitif yönlü anlamlı bir ilişki vardır. Psikolojik güçlendirmedeki artış, örgütsel bağl1lığın artmasına veya örgütsel bağl1lıktaki bir artışın çalışanın psikolojik olarak güçlenmesine neden olduğu görülmektedir. Regresyon analizi sonuçlarına göre ise psikolojik olarak güçlendirilmiş çalışanların örgütsel bağl1lığın duygusal ve normatif bağl1lık alt faktörlerini açıklamada etkisi olduğu görülmektedir. Devam alt boyutunda ise etki oldukça zayıftır. Sektörde eğitim seviyesinin düşük olması ve istihdamın mevsimsel nitelik taşımasının bu sonucun doğmasına neden olduğu değerlendirilmektedir.

Yoğun uluslararası rekabet koşulları içerisinde müşteri memnuniyetini hedef alan sektör ortaklarının, çalışanların asli unsur olduğunu unutmamaları ve çalışanların örgütsel bağlılıklarını güçlendirici faaliyetlerde bulunmaları gerekmektedir. Psikolojik güçlendirmenin de bu faaliyetlerden olduğu değerlendirilmektedir. Örgütler, iletişim kanallarını açık tutarak çalışanlarına yetki ve sorumluluk vermeli, becerilerini geliştirmek için fırsatlar sunmalı, öz yeterlilik duygularını geliştirmeli ve onları motive etmek için daha çok çaba sarf etmelidirler.

\section{KAYNAKLAR}

AKGÜNDÜZ, Y.; Kale, A.; Pazarbaș1, G. (2014), Futbol Turizmine Hizmet Eden Otel Calışanlarının Psikolojik Güçlendirme Algılarının Örgütsel Vatandaşlık Davranışlarına Etkisi; Mustafa Kemal Üniversitesi Sosyal Bilimler Enstitüsü Dergisi; Cilt 11, Say1 28

AKTOB (2014) Turizm İstatistikleri, www.aktob.org.tr 
ALLEN, N.J., Meyer, J.P. (1990): “The Measurement and Antecedents of Affective, Continuance and Normative Commitment to the Organization", Journal of Occupational Psychology, Cilt 63, Say1 1, ss.1-18.

ALLEN, N.J., Meyer J.P. (1991), A Three Component Conceptualization of Organizational Commitment, Human Resource Management Review, Volume 1, Number 1, 1991,61-89.

AMBAD, SYLVIZZ NABİLA AZWA; BAHRON, ARSİAH.(2012) Psychological Empowerment: The Influence on Organizational Commitment Among Employees in the Construction Sector; Journal of Global Business Management; Beaverton, 7381.

CEYLAN, A.K. - Çelik, G.M. - Emhan, A. (2015). Personel Güçlendirmesi ve Yönetici Desteğinin İş Memnuniyeti Üzerindeki Etkisi: Enerji Sektöründe Bir Uygulama, Journal of Business Research Turk, 7(1), 168-185.

ÇEKMECIOĞLU, H. ve Eren, E. (2007). Psikolojik güçlendirme, örgütsel bağlllık ve yaratıcı davranıs arasındaki ilişkilerin değerlendirilmesi. Yönetim, 18(57), 13-25.

ÇOLAKOĞLU, Ü., Ayyıldız , T., Cengiz, S. (2009) Çalışanların Demografik Özelliklerine Göre Örgütsel Bağlılık Boyutlarında Algılama Farklılıkları: Kuşadası'ndaki Beş Yıldızlı Konaklama İşletmeleri Örneği Anatolia: Turizm Araştırmaları Dergisi, Cilt 20, Say1 1, Bahar: 77-89.

DEMİREL, Y. Ve Yücel, İ. (2012), 'Psikolojik Güçlendirmenin Örgütsel Vatandaşl1k Davranışına Etkisi Üzerine Bir Araștırma', Kocaeli Üniversitesi Sosyal Bilimler Enstitüsü Dergisi, 23, ss. 19-48.

ERDEM, H., Gökmen, Y., Üren, U.,(2016) Psikolojik Güçlendirme Boyutlarının İş Performansı Üzerine Etkisinde Örgütsel Bağlılığın Aracılık Rolü: Görgül Bir Araştırma, Doğuş Üniversitesi Dergisi, 17 (2) 2016, 161-176.

GÜL, H., (2002). Örgütsel bağl1lık yaklaşımlarının mukayesesi ve değerlendirmesi, Ege Üniversitesi Ege Akademik Bakış Dergisi, Cilt:2 Sayı:1, 37-56.

GÜMÜŞTEKİN E., Emet G., (2007): “Güçlendirme Algılarındaki Değişimin Örgütsel Kültür ve Bağlılık Üzerine Etkileşimi”, Dumlupınar Üniversitesi Sosyal Bilimler Dergisi, Say1:17, s.90-116.

KARAHAN, A., Y1lmaz, H.,(2010) "Örgütsel Öğrenme, Personel Güçlendirme ve Takım Performansı Arasındaki İlişkilerin Analiz Edilmesi: Sağlık Sektöründe Bir Araştırma, Balıkesir Üniversitesi Sosyal Bilimler Enstitüsü Dergisi, Cilt 13, sayı 24, 153-171.

İSLAMOĞLU, A. H.; Alnıaçık, Ü. (2013). "Sosyal Bilimlerde Araştırma Yöntemleri" Beta Yayınları, İstanbul.

MEYDAN, C.H., Şeşen, H. (2015) Yapısal Eşitlik Modellemesi AMOS Uygulamaları, Detay Yayıncilik, Ankara

MORROW, P.C. (1983): "Concept Redundancy in Organizational Research: The Case of Work Commitment”, Academy of Management Review, Cilt 8, ss.486-500.

MOWDAY, R.T., STEERS, R.M. ve PORTER, L.W. (1979), "The Measurement of Organizational Commitment", Journal of Vocational Behavior, Cilt 14, ss.224247.

NAKTIYYK, A., Polat, F.,(2016) Çalışanların Psikolojik Taciz Algısının Örgütsel Bağlılıkla İlişkisi, Atatürk Üniversitesi İktisadi ve İdari Bilimler Dergisi, Cilt 30, Say1 1, 1 17.

ROYER, Linda (2009), Structural and Psychological Empowerment of Community/Public Health Nurses, (Ph. D. Thesis), George Mason University, Fairfax.

SPREİTZER, G. (1995) Psychological Empowerment in the Workplace: Dimensions, Measurement and Validation; Academy of Management Journal, Vol. 38, No 5, 1442-1465

TABACHNİ, B. G. ve Fidel, L. S. (2007). Using Multivariate Statistics. 5th Ed., Boston: Pearson Edu. Inc. 
TOLAY E., Sürgevil O., Topoyan M. (2012). Akademik Çalışma Ortamında Yapısal Ve Psikolojik Güçlendirmenin Duygusal Bağll1ık Ve İș Doyumu Üzerindeki Etkileri. Ege Akademik Bakıs, Cilt: 12 S: 4 • Ekim 2012, 449-465.

WHYTE, W. (1956). "The organization man”. Garden City, NY: Doubleday Anchor Books.

YÜCEL, I. ; Demirel, Y. (2012) "Psikolojik Güçlendirmenin Örgütsel Vatandaşlık Davranışına Etkisi Üzerine Bir Araştırma" Kocaeli Üniversitesi Sosyal Bilimler Enstitüsü Dergisi, 23

YÜKSEL, Ö. ve Erkutlu, H. (2003) "Personeli Güçlendirme” Gazi Üniversitesi İktisadi ve İdari Bilimler Fakültesi Dergisi, 1:131-142. 